\title{
Participatory Design for Users with Impairments Affecting Cognitive Functions and Communication Skills
}

\author{
Karin Slegers \\ Centre for User Experience Research (CUO) \\ KU Leuven/IBBT \\ Parkstraat 45, 3000 Leuven, Belgium \\ karin.slegers@soc.kuleuven.be
}

Pieter Duysburgh
IBBT-SMIT/VUB

Pleinlaan 9, 1050 Brussels, Belgium

pieter.duysburgh@vub.ac.be

\author{
Helma van Rijn \\ ID-StudioLab, TU Delft \\ Landbergstraat 15, 2628 CE Delft, Netherlands \\ h.vanrijn@tudelft.nl
}

\begin{abstract}
Involving people with impairments in the design process is very challenging, especially when impairments affect cognitive functions or communication. People with such impairments may have substantial problems with thought processes and communication, including understanding abstractions, sequencing thoughts and actions, understanding symbols, and interpreting social cues. Many participatory design techniques are based on these processes and are therefore not usable, or need to be adjusted for people with impairments. This workshop aims to exchange experiences with participatory design techniques that were designed for, or adapted to people with impairments. Since many of these techniques are highly focused on specific target groups, a further aim is to extract general principles and to generate guidelines for involving users with impairments in the design process.
\end{abstract}

\section{Author Keywords}

Impairments, Tools \& Techniques, User involvement, Participatory design

\section{ACM Classification Keywords}

H5.m. Information interfaces and presentation: Miscellaneous.

\section{INTRODUCTION}

Researchers and designers need to understand the lives and experiences of end-users to increase the likelihood that products and services fit these users and enhance their lives (Koskinen et al. 2003). Ideally, end-users actively participate in all research and design activities, such as problem definition, ideation, design, development and evaluation. Several tools and techniques have been developed to involve the users in these activities and to gain a deep understanding of the users and their lives.

Permission to make digital or hard copies of all or part of this work for personal or classroom use is granted without fee provided that copies are not made or distributed for profit or commercial advantage and that copies bear this notice and the full citation on the first page. To copy otherwise, or republish, to post on servers or to redistribute to lists, requires prior specific permission and/or a fee.

PDC '12, August 12 - 16 2012, Roskilde, Denmark

Copyright 2012 ACM 978-1-4503-1296-7/12/08 ... \$10.00
Niels Hendriks

Social Spaces Research, MAD-Faculty/Fac. of Arts \& Architecture KU Leuven

C-Mine 5, 3600 Genk, Belgium niels.hendriks@khlim.be

Examples of such methods are contextual inquiry, (participatory) observations, design probes, low-tech prototyping, design games and generative toolkits.

When designing for users with impairments it is especially important to understand the users and their experiences, and more specifically the issues users face because of their limitations (Henry, Law \& Barnicle, 2001). However, understanding users with impairments is challenging, especially when the impairments affect cognitive abilities or communication skills, such as Autism Spectrum Disorder, Alzheimer's Disease or hearing impairments. The experiences of users with such impairments might be very different from those of the researchers and designers, making it difficult to identify with or relate to the users. In addition, these users often experience problems with thought processes and communication, including conceptualizing and understanding abstractions, sequencing thoughts and actions, remembering, understanding symbols, and interpreting social cues. These problems may cause difficulties with making sense of and sharing experiences verbally with others (Braddock et al., 2004).

Many research and design techniques for involving users draw upon the cognitive functions or communication skills that users with impairments have problems with. They are based on a shared verbal or visual language, make use of symbols or require the participants to conceptualize and think creatively. These techniques might therefore not be usable or have to be adjusted for people with impairments (Lazar, Feng and Hochheiser, 2010). A critical issue is that for each user group, adjustments to techniques have to be thought of, while the main principles behind the adjustments are not always clear. The main goal of this workshop is to extract exactly those principles in order to set up guidelines for doing participatory design with users with impairments that affect cognitive functions and communication.

\section{WORKSHOP GOAL}

This workshop aims to 1) bring together people who are active in the topic of the workshop to create a community; 2) exchange ideas about and experiences 
with tools and techniques for specific groups of users with impairments; and 3) identify general principles and guidelines for doing participatory design with users with impairments.

\section{WORKSHOP FORMAT}

\section{Participants}

All researchers and designers who have been involved in one or more design-oriented project(s) involving users with impairments are invited to participate. For the purpose of this workshop, we define users with impairments as 'users with impairments that affect cognitive functions or communication' (such as hearing impairments, visual impairments, autism, dementia, or amnesia). Especially researchers and designers who have worked with such user groups, and who have used (adjusted) tools or techniques to understand and involve these users are encouraged to participate. A maximum of 25 people can participate.

People can apply and prepare for the workshop, by filling in a set of workshop cards (see Fejl! Henvisningskilde ikke fundet. for an example) which they can download from the workshop website: http://pdcimpairmentsworkshop.wordpress.com/ . On

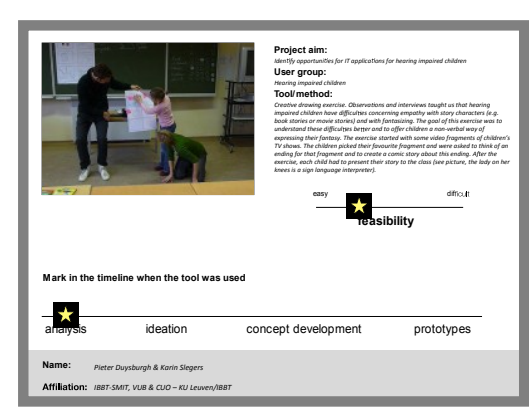

Figure 1 Example of a workshop card each card, participants add information about the target group they worked with, a short description of a tool or technique they used, the phase of the design process in which the tool or technique was used, and a picture (if available). One card per specific user group and/or tool or technique is requested. Besides filling in the cards, applicants are required to write a one-pager about their expectations of the workshop and the specific topics they would like to discuss.

\section{Setup of the workshop}

This full-day workshop will have a creative, generative character. It will refrain from using a standard workshop setup of presentations and discussions. Instead, sharing best practices, brainstorms and adjusting techniques will be at the core of all activities.

The workshop will consist of four parts:

\section{Introduction}

In the first part of the workshop, participants will introduce themselves and share how they think the specific users they work with should be approached. To stimulate this discussion, we invite the participants to share anecdotes of failed and successful attempts in working with their user group. A group discussion will focus on practical problems and solutions for approaching and involving users with impairments in research and design activities. The goal of this first part is mainly to get to know each other and to have a platform to informally share best practices and common problems.

\section{Organizing methods}

In the second part of the workshop, the cards the participants prepared will be placed on a large scheme including all phases of the design process, possible stakeholders involved and the target groups represented in the workshop. This will allow all participants to briefly explain their tools and techniques. Cards focusing on similar target groups will be placed at the same level of the scheme so as to create a clear overview of tool and techniques that have been used for specific target groups in specific design phases.

\section{Elaborating and adjusting methods}

In the third part, the participants will be split up in small groups, based on the specific user groups the participants have experience with. Each group will choose one of the cards describing a tool or technique, which is relevant for their mutual target group. This card will be discussed into more detail, resulting in a new, more elaborate description of the tool or technique (e.g., in terms of approach, material, and results). After this discussion, the groups exchange cards. Each group now discusses a tool or technique, which was originally used with other endusers than their mutual target group. They discuss how the tool or technique could be adapted to be of use for their target group. They will indicate which elements will have to be changed (and how), which elements can be maintained and which elements have to be eliminated. This process of elaborating and adapting will be repeated a number of times as time allows.

\section{Extracting general principles and guidelines}

In the fourth part, a plenary presentation and discussion of the adapted tools and techniques will be held. The changes and the maintained elements will be a central focus during the discussion. The final aim of this discussion, and of the workshop in general, is to identify those elements of the tools and techniques that can be applied to multiple target groups, to derive general principles of involving and understanding users with impairments.

\section{REFERENCES}

Braddock, D., Rizzolo, M.C., Thompson, M. \& Bell, R. Emerging technologies and cognitive disability, Journal of Special Education Technology, 2004, 19(4): p. 49-56.

Henry, S.L., Law, C., and Barnicle, K. Adapting the design process to address more customers in more situations. Proc. UPA Conference 2001,

Koskinen, I., Battarbee, K., \& Mattelmäki, T. Empathic Design, User experience in Product Design. IT Press, Helsinki, Finland. 2003.

Lazar, J., Feng, J.H., \& Hochheiser, H. Research Methods in Human-Computer Interaction. John Wiley \& Sons Ltd., Chichester, UK. 2010. 